\title{
Plasma level of atrial natriuretic peptide during normal pregnancy and preeclampsia
}

\author{
Abdul-Aziz Ahmed Aziz \\ Department of Physiology, College of Medicine, University of Mosul
}

(Ann. Coll. Med. Mosul 2005; 31(1): 1 - 5)

Received:20 Feb 2005 ; Accepted: $25^{\text {th }}$ Sept 2005

\begin{abstract}
Objective: To assess plasma atrial natriuretic peptide (ANP) level in pregnant and freeclamptic women, and to evaluate the role of this hormone in the defense mechanism against body fluids and electrolytes disorders encountered under such physiological
\end{abstract} and pathophysiological conditions.

Design: A case- series study.

Setting: Al - Batool Teaching Hospital for Gynecology and Obstetrics, Mosul, during the period from December 2003 to September 2004.

Participants: Twenty five women with normal pregnancy (group | ), 25 pregnant women with preeclampsia (group II) and 25 healthy non pregnant women (control group) were included in ihis study.

Methods: Plasma ANP, serum creatinine, urea, sodium and potassium were measured in all groups. unpaired -t-test was used to examine the difference in the mean of the studied parameters between different groups. Pearson correlation was used to assess the relation between different parameters within each group.

Results: The mean of plasma ANP level was significantly higher in group I $(p<0.05)$ and group If $(p<0.0001)$ than that in the control group. Furthermore, the plasma ANP level was significantly higher in group II $(p<0.0001)$ than that in group I. The mean of serum creatinine and serum urea were significantly higher in group II than that in groupl $(p<0.005$ and $p<0.0001)$ and control group ( $p<0.0001$ and $p<0.0001$ ).

Conclusion: The results of this study indicate that plasma ANP level significantly increases curing pregnancy especially among those who develop preeclampsia. Since ANP plays an important role in the maintenance of body fluids and electrolytes homeostasis and blood pressure regulation, estimation of plasma ANP level may be of value in better understanding and management of pathophysiological conditions that challenge the body homeostatic mechanisms during pregnancy.

Key words: Atrial natriuretic peptide, preeclampsia.

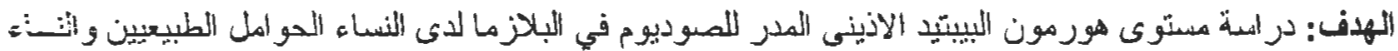

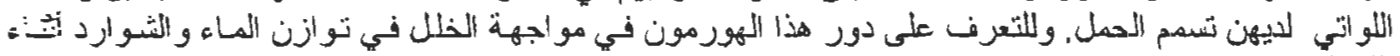

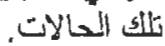

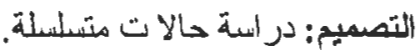

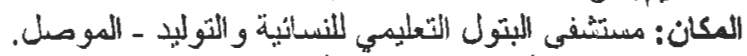

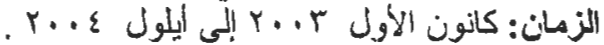

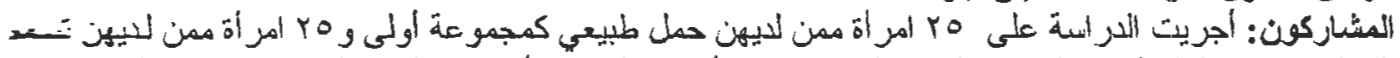

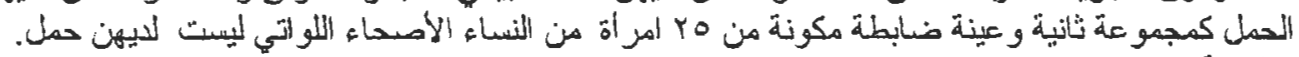

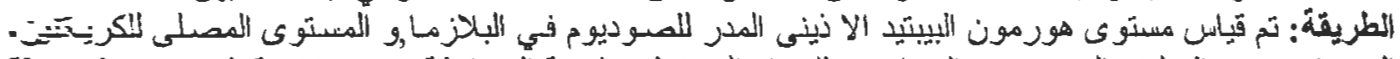

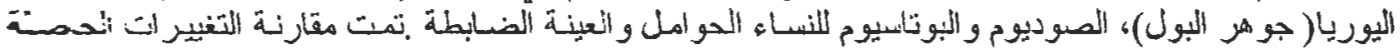




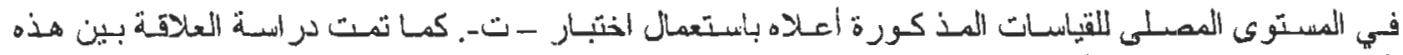

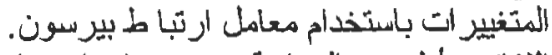

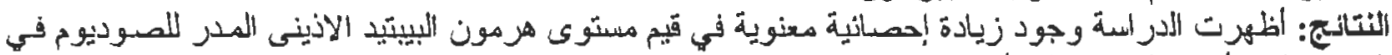

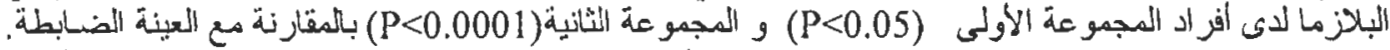

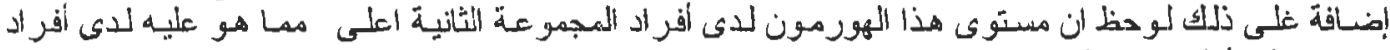

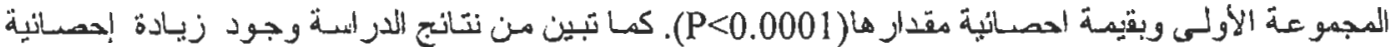

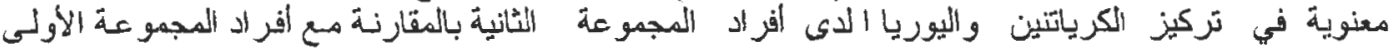

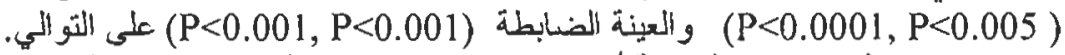

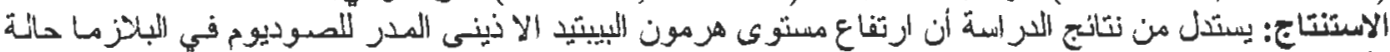

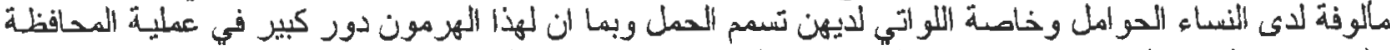

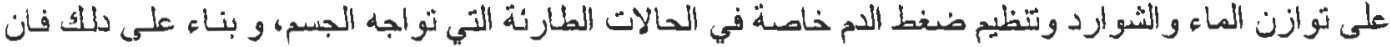

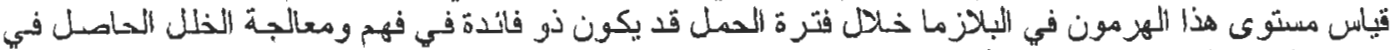
تو ازن الماء و الثشوارد في الجيسم انتاء تلك الفقترة.

$\mathrm{T}$ he major hemodynamic changes induced by pregnancy include reduction in systemic vascular resistance and systemic blood pressure leading to sodium and water retention and blood volume expansion ${ }^{(1)}$ with subsequent increase in cardiac output. Plasma volume increases by 10 to 15 percent at 6 to 12 weeks of gestation and expands rapidly until 30 to 34 weeks, after which there is only a modest rise. The total gain at term averages 1100 to $1600 \mathrm{ml}$ and results in a plasma volume which is, 30 to 50 percent above that found in nonpregnant wornen ${ }^{(2)}$. The gradual development of hypertension, proteinuria, and edema in pregnancy is most often due to preeclampsia, particularly in a primigravida. Preeclampsia occurs in approximately 6 to 8 percent of all pregnancies worldwide, and characterized by generalized vasospasm, activation of the coagulation system, and changes in several humoral and autoregulatory systems related to body fluid volume and blood pressure control ${ }^{(3)}$. Atrial natriuretic peptide is known to have natriuretic, diuretic, vasorelaxant properties and may have antagonistic effects on the renin-angiotensin -aldosterone system. Thus, it is thought to participate in the normal homeostatic mechanisms that maintain the composition and volume of the body fluids ${ }^{(4,5)}$

The aim of this study was to determine the rate of increment in the plasma level of ANP in normal pregnancy and in preeclampsia, and to evaluate the role of this hormone in the defense mechanism against body fluids and electrolytes disorders encountered under such physiological and pathophysiological conditions.

\section{SUBJECTS, MATERIALS AND METHODS}

The study included 25 women with normal pregnancy (group 1), their age ranged from $18-40$ years with a mean \pm SD of $(26.72$ $\pm 8.15)$ and 25 preeclamptic pregnant women (group II), their age ranged from $17-39$ years $(25.60 \pm 7.95)$ in their third trimesters. All were selected from those who attend outpatient clinics of $\mathrm{Al}$ - Batool Teaching Hospital for Gynecology and Obstetrics, Mosul, for their periodic pregnancy examinations, during the period from December 2003 to September 2004. All women included in the study had no evidence of renal and for cardiovascular disorders. Since hypertension in the third trimester is defined as a blood pressure of $140 / 85 \mathrm{mmHg}$ or greater that is sustained during repeated measurements for 6 hours $^{(6)}$, all selected preeclamptic women had blood pressures $\geq 140 / 85 \mathrm{mmHg}$, associated with proteinuria and edema. The study also included 25 apparently healthy non pregnant women as control group. Their age ranged from $15-38$ years, with a mean $\pm S D$ of $(24.5 \pm 6.11)$.

Ten $\mathrm{ml}$ of venous blood was obtained from a suitable forearm vein. Five $\mathrm{ml}$ of the sample was collected in a heparinized tube and immediately placed in ice for the measurement of the plasma ANP level. The other $5 \mathrm{ml}$ was placed in plain tube for the measurement of serum creatinine, urea, sodium and potassium levels. Both tubes were centrifuged within 30 minutes, the plasma and serum then separated and kept frozen in capped plastic tubes at (-20C) until analysis. Plasma ANP concentration was determined by Enzyme Linked ImmunoSorbent Assay (ELISA) (7) utilising kit provided by DRG International inc., USA. (Cat.. No. : Eia1524). Serum creatinine was measured manually by Jaffe end point method ${ }^{(8)}$ using 
kit from Randox colorimetric (with deproteinization). Serum urea concentration was determined enzymatically. In an alkaline medium, the ammonium ions react with the phenol and hypochlorite to form a green colored indophenol $^{(9)}$. Serum sodium and potassium levels were measured by flame photometer (Corning 400 England) ${ }^{(10)}$. Statistical analysis was performed using unpaired-t-test to assess the differences in the mean of plasma ANP, serum creatinine, urea, sodium and potassium level between different groups. Pearson correlation coefficient test was used to study the relation between the different studied parameters within each patient group. All values were expressed as mean $\pm \mathrm{SD}$.

\section{RESULTS}

The mean $\pm S D$ of plasma ANP, serum creatinine, urea, sodium and potassium of group I, group || and control group are shown in Table 1. The mean of plasma ANP level was significantly higher in groupl $(p<0.05)$ and group II $(p<0.0001)$ than that in control group. Furthermore, the plasma ANP level was significantly higher in group II ( $p<0.0001$ ) than that in group I, (Fig 1). The means of serum creatinine and serum urea were significantly higher in group II than those in groupl $\quad(p<0.005$ and $p<0.0001)$ and control group $(p<0.0001$ and $p<0.0001$ ) r espectively. There $w$ as no correlation between plasma ANP level and serum creatinine nor between plasma ANP level and serum urea both in group and group II. There were no significant differences in serum sodium and potassium concentration between group 1 and group II themselves nor between these groups and the control group.

Table (1): The mean \pm SD of plasma ANP, serum creatinine, urea, sodium and potassium of group I, group II and control group.

\begin{tabular}{|c|c|c|c|}
\hline \multirow[b]{2}{*}{ Paramelers } & \multicolumn{3}{|c|}{ Mean \pm S.D. } \\
\hline & Control group, $N=25$ & Groupl, $N=25$ & Group II, $N=25$ \\
\hline \multirow{2}{*}{$\begin{array}{l}\text { Plasma ANP } \\
\mathrm{pg} / \mathrm{ml}\end{array}$} & $34.84 \pm 5.52$ & $39.08 \pm 4.98$ & $49.96 \pm 10.09$ \\
\hline & $A, B$ & \multicolumn{2}{|c|}{$P<0.0001$} \\
\hline \multirow{2}{*}{$\begin{array}{l}\text { Serum creatinine } \\
\mu \mathrm{mol} / \mathrm{I}\end{array}$} & $84.48 \pm 8.94$ & $88.96 \pm 7.28$ & $99.80 \pm 15.22$ \\
\hline & $B$ & \multicolumn{2}{|c|}{$p<0.005$} \\
\hline \multirow{2}{*}{$\begin{array}{l}\text { Serum urea } \\
\mathrm{mmol} / \mathrm{l}\end{array}$} & $4.44 \pm 0.62$ & $4.64 \pm 0.73$ & $6.14 \pm 0.96$ \\
\hline & $B$ & \multicolumn{2}{|c|}{$P<0.0001$} \\
\hline \multirow{2}{*}{$\begin{array}{l}\text { Serum sodium } \\
\mathrm{mmol} / \mathrm{l}\end{array}$} & $138.16 \pm 2.15$ & $137.28 \pm 2.38$ & $136.88 \pm 2.18$ \\
\hline & NS & \multicolumn{2}{|l|}{ NS } \\
\hline \multirow{2}{*}{$\begin{array}{l}\text { Serum potassium } \\
\mathrm{mmol} / \mathrm{l}\end{array}$} & $3.82 \pm 0.16$ & $3.78 \pm 0.21$ & $3.72 \pm 0.23$ \\
\hline & NS & \multicolumn{2}{|l|}{ NS } \\
\hline
\end{tabular}

A : significantly higher in groupl from respective values in control group.

B : significantly higher in groupll from respective values in control group.

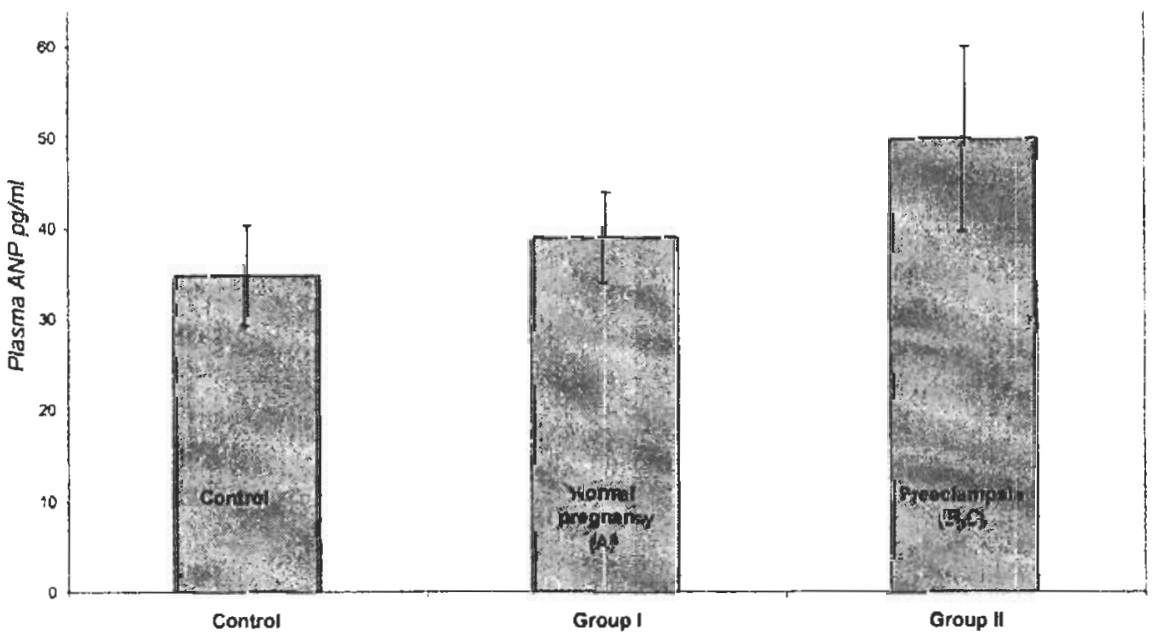

Figure (1): The mean $\pm S D$ of plasma ANP in groupl, group $\mid 1$ and control group (A: significantly higher in groupl from respective values in control group, $B$ : significantly higher in group II from respective values in control group, $C$ : significanlly higher in group (I from respective values in groupl). 


\section{DISSCUSSION}

Pregnancy is associated with a variety of maternal hemodynamic changes, which are compensatory in nature. The majority of these changes are triggered by systemic vasodilatiation which results in reduction of plasma volume and stimulation of reninangiotensin-aldosterone system activity with subsequent water and sodium retention $^{(11)}$. In normal pregnancy there is approximately $50 \%$ increase in the total extracellular fluid and blood volumes, which are the results of about (700-1000) mmol sodium retention ${ }^{(2)}$. Many studies have documented relative hypovolemia in preeclampsia in comparison with normal pregnancy ${ }^{(i 2)}$. Accordingly, preeclamptic pregnants have always had a sense of reduced plasma volume; this will initiate a number of compensatory mechanisms to counteract the intravascular volume contraction leading to extra sodium and water retention in preeclampsia(13). The results of this study showed a significantly higher plasma ANP level in group 1 and group II in comparison with control group ( $p<0.05$ and $p<0.0001)$. Furthermore, the plasma ANP level in group II was significantly higher than that in group 1 ( $p<0.0001)$. Increased blood volume during normal pregnancy as well as in preeclamplic women represents an ideal model for increase of intra-atrial pressure which leads to stretching of the atrial wall and subsequent release of ANP by atrial myocyte ${ }^{(14)}$. In addition to this mechanism a transplacental crossing of ANP secreted by fetal heart and placenta, might be, at least in part responsible for the high ANP level observed in preeclampsia(15). Plasma creatinine and plasma urea levels in group II were significantly higher than those in group $1 \quad(p<0.005$ and $p<0.0001)$ and control group $(p<0.0001$ and $p<0.001)$ respectively. These changes are probably due to clecreased giomerular filtration rate with subsequent creatinine and urea retention ${ }^{(16)}$. The results of this study indicate that an early detection of abnormally high levels of plasma ANP in pregnant women may be an indirect indicator of body fluids and electrolytes imbalance and a possible predictor of preeclampsia during pregnancy.

\section{REFERENCES}

1. Brown MA. Sodium and plasma volume regulation in normal and hypertensive pregnancy: A review of physiology and clinical implications. Clin and Exper Hyper in Pregnancy 1988; B7: 265-282.

2. B renstein I $M$, Ziegler $W$, Badger GJ. Plasma volume expansion in early pregnancy.

Obstet

Gynecol

2001;97:669-672.

3. Sibai BM, Caritis S, Hauth J. What we have learned about preeclampsia. Semin Perinatol $2003 ; 27$ : 239-246.

4. Nakamura S, Naruse $M$, Naruse $K$, et al. Atrial natriuretic peptide and brain natriuretic peptide coexist in the secretory $g$ ranules of human cardiac myocytes. Am. J Hypertens 1991;4:909912.

5. Naruse $M$, Takeyama $Y$, Tanabe $A$, et al. A trial and brain natriuretic peptides in cardiovascular diseases. Hypertension 1994 23: 1231-1234.

6. Helewa ME, Burrows RF, Smith $\rfloor$, et al. Report of the Canadian Hypertension Society Consensus Conference : 1. Definition, evaluation and classification of hypertensive disorders in pregnancy. CMAJ 1997;157:715-725.

7. Porstmann T, Kiessig ST. Enzyme immunoassay techniques, an overview. J Immuno Methods 1992 ; $150: 5-21$

8. Spencer K. Analytical reviews in clinical biochemistry, the estimation of creatinine. Ann C lin B iochem $1986 ; 23$ : $1-25$.

9. Wootton IDP, Freeman $H$. Microanalysis in medical biochemistry. $6^{\text {th }}$ ed, New York, Churchill Livingstone, 1982, 64-66.

10. Evensuri MA. Spectrophotometric techniques. In Burtis $\mathrm{CA}$ and Ashwood ER (Eds). Tietz textbook of clinical chemistry. $3^{\text {rd }}$ ed Philadelphia: W.B. Saunders company, 1999, 86-90.

11. D uvekot J J, Cheriex EC, P ieters FAA. et al. Early pregnancy changes in hemodynamic and volume homeostasis are consecutive adjustments $t$ riggered by a primary fall in systemic vascular tone. Am J Obstet Gynecol 1993 ; 169 :1382-1392.

12. Hays PM, Cruikshark DP, Dunn LJ Plasma volume determination in normal and preeclamptic pregnancies. Am J Obstet Gynecol 1985; 151 : 958-966.

13. Schrier RW, Briner VA. Peripheral arterial vasodilatation hypothesis of sodium and water retention in pregnancy : Implications for pathogenesis of preeclampsiaeclampsia. Obstet Gynecol 1991; 77:632-639.

14. Lang RE, Tholken $H$, Ganten $D$, et al. Atrial natriuretic factor-a circulating hormone stimulated by volume loading. Nature 1985; $314: 264-267$.

15. Furuhashi $N$, Tsujiei $M$, Kimura $H$, Yajima A, Nagae H, Kimura C. Maternal 
and fetal atrial natriuretic peptide levels, maternal plasma renin activity, angiotensin II, prostacyclin and thromboxane A 2 levels in normal and preeclamptic pregnancies. Tohoku $J$ Exp Med 1991; 165: 79-86.
16. Moran $\mathrm{P}$, Baylis $\mathrm{PH}$, Lindheimer MD, Davison JM . Glomerular ultrafiltration in normal and preeclamptic pregnancy. J Am Soc Nephrol 2003; 14: 648-652. 